\title{
Painless Legs and Moving Toes Presenting as a Tardive Phenomenon: Case Report and Review of the Literature
}

\author{
Elanagan Nagarajan ${ }^{1}$ Lakshmi P Digala² Pradeep C Bollu² \\ ${ }^{1}$ Department of Neurology, Columbia University, New York, \\ United States \\ 2Department of Neurology, University of Missouri, Columbia, \\ Missouri, United States \\ Address for correspondence Elanagan Nagarajan, MD, Department \\ of Neurology, Columbia University, New York, 10032, United States \\ (e-mail: en2452@cumc.columbia.edu).
}

J Neurosci Rural Pract 2020;11:341-342

\begin{abstract}
Painless legs and moving toes syndrome is a rare movement disorder. Various conditions like spinal cord trauma, lumbar radiculopathy, peripheral neuropathy, neuroleptic treatment, or traumatic lesions of the soft tissues of the foot can present with this

Keywords

- painless legs and curly toes disorder. In our case report, we aim to report a case of a young woman who developed painless legs and moving toes in the setting of chronic neuroleptic usage, which improved after the discontinuation of antipsychotics and treatment with clonazepam.

- movement disorder

- tardive dyskinesias We describe in detail her presentation and clinical examination, along with the review of the literature.
\end{abstract}

\section{Introduction}

Painless legs and moving toes syndrome is a rare variant of painful leg and moving toes, which itself is a rare movement disorder. Both conditions cause semi-continuous movements of the toes, and sometimes of fingers, jaw, and tongue. ${ }^{1,2}$

Walters et al first reported this condition in 1993. ${ }^{3}$ Since then, few other patients with this condition have been reported. We describe a female with painless legs and moving toes in the setting of chronic neuroleptic usage.

\section{Case Presentation}

A 48-year-old Caucasian female who presented to our outpatient clinic with a chief complaint of involuntary curling of toes in both of her feet. Her symptoms started initially almost 1 year ago in her right foot and 9 months later in her left foot. The curling of the toes was not painful, but the calluses formed on her toes as a result were shown in Fig. 1A-D. The movements occurred regularly every 2 to 3 seconds, and she could only voluntarily suppress for a brief period. The movements were very stereotypical, restricted to toes, and disappeared in sleep. She has multiple psychiatric comorbidities, including bipolar disorder and posttraumatic stress disorder, and has been on various psychotropic medications. She was on aripiprazole, lithium, escitalopram, and bupropion at the time of her presentation. She also has a history of tardive dyskinesias in the past, which resolved after some time. The initiation of benztropine resulted in the improvement in her curling toes, but brought on orofacial dyskinesias. A trial of amantadine was not successful due to intolerance. Within a week of starting amantadine, she also developed truncal dyskinesias. Her psychiatrist discontinued her aripiprazole and started on quetiapine. Interestingly, the patient did not have any worsening of abnormal movements with quetiapine. We started the patient on clonazepam, which eventually resulted in improvement in her truncal dyskinesias and curling toes.

\section{Discussion}

Painful legs and moving toes is a rare disease that constitutes painful legs and involuntary movements of toes. In 1971, Spillane et al first described this in about six patients who complained about the pain in one or both feet and showed abnormal movements in the distal lower limbs. ${ }^{4}$ Various conditions like spinal cord trauma, lumbar radiculopathy, peripheral neuropathy, neuroleptic treatment, or traumatic lesions of the soft tissues of the foot can present with this, of which spinal cord lesions are the most common. ${ }^{5-8}$ 

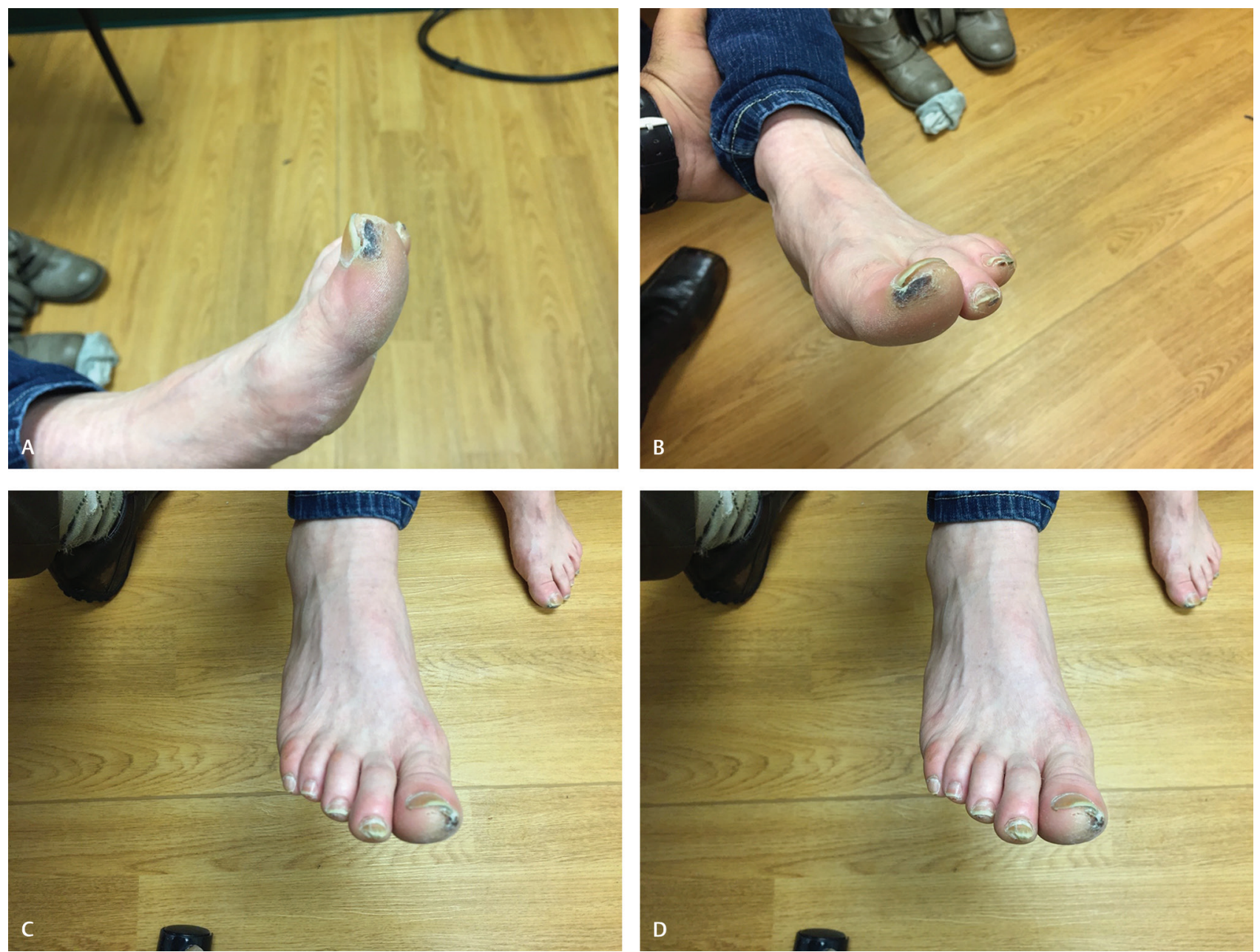

Fig. 1 (A-D) The toes show the calluses that were formed due to the constant curling of the toes. The curling itself was not painful but the resultant calluses were painful.

In a subset of those patients, similar movements were noticed without any associated pain and this was described as a separate entity of painless legs and moving toes syndrome by Walter et al. ${ }^{3}$ This syndrome consists of continuous or semi-continuous involuntary writhing movements of the toes without any associated pain in the affected extremity. These movements include torsion, abduction, adduction, flexion, and extension movements of toes with the absence of pain.

Walters et al described a case of a 59-year-old man who had progressive worsening of involuntary toe movements that started 34 years earlier without any associated pain in 1993. ${ }^{3}$ A year later, Dressler et al described three other cases, one of whom had severe dysraphism, while the other two did not have any spinal cord pathology. ${ }^{5} \mathrm{~A}$ similar syndrome was described in a mother and her daughter in 2003 by Dziewas et $\mathrm{al}^{9}{ }^{9}$ and neither of them had any other associated medical conditions. ${ }^{7}$ Bermejo and Zabala described a case in an older woman in the setting of thoracic spinal cord compression in whom gabapentin was found to be effective. ${ }^{10}$ The pathophysiology of this condition remains unclear, and many believe that both the painless and the painful legs and moving toes are the same entity. Alterations in the afferent sensory information due to a peripheral injury and subsequent reorganization of segmental and suprasegmental efferent motor activity may be behind the abnormal movements.

The diagnosis is primarily clinical, and the treatment is complex, involving different combinations of drugs and invasive techniques. Given the rarity of cases, there are no randomized controlled trials on the pharmacological management of this condition. Based on evidence from a few case reports, clonazepam, baclofen, and gabapentin appear to be effective. ${ }^{7}$

\section{Note}

This study was approved by Institutional Board Review of University of Missouri Health Care-Columbia.

\section{Funding}

None.

\section{Conflict of Interest}

None declared.

\section{References}

1 Funakawa I, Mano Y, Takayanagi T. Painful hand and moving fingers. A case report. J Neurol 1987;234(5):342-343

2 Verhagen WI, Horstink MW, Notermans SL. Painful arm and moving fingers. J Neurol Neurosurg Psychiatry 1985;48(4): 384-385 
3 Walters AS, Hening WA, Shah SK, Chokroverty S. Painless legs and moving toes: a syndrome related to painful legs and moving toes? Mov Disord 1993;8(3):377-379

4 Spillane JD, Nathan PW, Kelly RE, Marsden CD. Painful legs and moving toes. Brain 1971;94(3):541-556

5 Dressler D, Thompson PD, Gledhill RF, Marsden CD. The syndrome of painful legs and moving toes. Mov Disord 1994;9(1):13-21

6 Montagna P, Cirignotta F, Sacquegna T, Martinelli P, Ambrosetto G, Lugaresi E. "Painful legs and moving toes" associated with polyneuropathy. J Neurol Neurosurg Psychiatry 1983;46(5): 399-403
7 Sandyk R. Neuroleptic-induced "painful legs and moving toes" syndrome: successful treatment with clonazepam and baclofen. Ital J Neurol Sci 1990;11(6):573-576

8 Wulff $\mathrm{CH}$. Painful legs and moving toes. A report of 3 cases with neurophysiological studies. Acta Neurol Scand 1982;66(2): 283-287

9 Dziewas R, Kuhlenbäumer G, Okegwo A, Lüdemann P. Painless legs and moving toes in a mother and her daughter. Mov Disord 2003;18(6):718-722

10 Bermejo PE, Zabala JA. "Painless legs and moving toes" syndrome due to spinal cord compression. Eur Spine J 2008;17(2(Suppl 2) :S294-S295 